\title{
Characterization and microstructure of porous lead zirconate titanate ceramics
}

\author{
B PRAVEENKUMAR, H H KUMAR and D K KHARAT* \\ PZT Centre, Armament Research and Development Establishment, Pune 411 021, India
}

MS received 9 December 2004; revised 10 March 2005

\begin{abstract}
Porous lead zirconate titanate (PZT) ceramics are widely used because of their low acoustic impedance, high figure of merit and high hydrostatic sensitivity. In the present work, porous PZT ceramics were fabricated by incorporating polyethylene oxide (PEO) as pore-forming agent. Both PZT powder and PEO were mixed with a binder at different ratios and compaction was carried out. The samples were slowly heated to remove the pore-forming agent and binder without cracks, followed by controlled sintering and electrode forming. Samples were poled using corona poling technique. The ferroelectric properties and microstructure of the prepared ceramics were characterized. The correlation of porosity with microstructure and ferroelectric properties were discussed.
\end{abstract}

Keywords. Porous PZT; corona poling; ferroelectric properties.

\section{Introduction}

Lead zirconate titanate (PZT) plays a prominent role in modern electroceramic industry. Its applications cover ultrasonic and underwater transducers, nonvolatile memory elements, pyroelectric detectors and photoelectric devices (Newnham and Ruschau 1991; Haertling 1999; Ramesh et al 2004). For underwater transducer applications we need to have porous piezoelectric materials. These can be made by combining a PZT ceramic with a passive polymer or air phase. These materials greatly extend the range of properties offered by conventional PZT ceramics. Moreover, porosity in the materials could reduce the effective acoustical impedance leading to an improved acoustic matching between the component and the media through which signals are transmitted or received (Roncari et al 2001; Li et al 2003; Praveenkumar et al 2004).

Piezoelectric sensitivity, charge generated per unit force or electric field generated per unit stress, is an important parameter for heterogeneous ferroelectric materials. The need for increased piezoelectric sensitivity has led to the study of optimization of processing parameters and novel porous ceramics structures (Newnham 1997). Depending on the transducer applications, piezoelectric sensitivity is characterized by a set of parameters or figures of merit, such as hydrostatic voltage coefficient $\left(g_{\mathrm{h}}\right)$, hydrostatic charge coefficient $\left(d_{\mathrm{h}}\right)$ and hydrostatic figure of merit $\left(d_{\mathrm{h}} \times g_{\mathrm{h}}\right)$. Composites with large figures of merit offer considerable advantages over single crystal or monolithic polycrystalline ceramics in hydrophone and related underwater applications (Bowen and Topolov 2003).

\footnotetext{
*Author for correspondence (tircarde@ vsnl.com)
}

In the present study, porous PZT materials were characterized for hydrostatic and piezoelectric charge coefficients. The correlation of porosity with the properties and microstructure are discussed.

\section{Experimental}

PZT powders were synthesized from commercially available $\mathrm{PbO}, \mathrm{ZrO}_{2}, \mathrm{TiO}_{2}, \mathrm{La}_{2} \mathrm{O}_{3}$ and $\mathrm{Nb}_{2} \mathrm{O}_{5}$ powders. The weighed powders were calcined in a high temperature furnace at $950^{\circ} \mathrm{C}$ for $30 \mathrm{~min}$. After drying and granulating, the calcined powder was mixed with PEO and polyvinyl alcohol at different volume ratios of PZT/PEO as 50/50, $60 / 40,80 / 20$ in agate pestal mortar. The mixed powder was compacted to $22 \mathrm{~mm}$ disks by uniaxial pressing machine and fired at $550^{\circ} \mathrm{C}$ for $9 \mathrm{~h}$ to burn out the binder. The specimens were stacked in a hermetically sealed alumina crucible and sintering was carried out at $1250^{\circ} \mathrm{C}$ for $30 \mathrm{~min}$. The specimens were poled by using corona poling technique (Waller and Safari 1988).

The density of the sintered components was measured from its mass and dimensions. The microstructure of sintered component was examined by a FEI, Quanta 200 Scanning Electron Microscope. The ferroelectric properties were measured using copper adhesive foils. The dielectric, piezoelectric and hydrostatic properties were measured using LF impedance analyser (HP 4192A) and dual range piezometer system (Take Control PM 35).

\section{Results and discussion}

Figure 1 shows the density of specimens in relation to amount of PEO added. The density of the specimen 
decreases with increase in the amount of PEO, which subsequently decreases the acoustic impedance of material to be matched with water. Consequently as the density of the material decreases its porosity increases followed by subsequent increase in the hydrostatic coefficients.

Figure 2 indicates the effect of hydrostatic charge coefficient $\left(d_{\mathrm{h}}\right)$ and hydrostatic voltage coefficient $\left(g_{\mathrm{h}}\right)$ with increase in the amount of PEO. It is observed that $d_{\mathrm{h}}$ increases with increase in the amount of PEO. The peak value of $d_{\mathrm{h}}$ was observed at (50/50) PZT/PEO. The improved $d_{\mathrm{h}}$ with this composition of porous PZT ceramics is due to the effective anisotropy in the microstructure which also decreases the dielectric constant of the specimens. Similarly $g_{\mathrm{h}}$ also increases with increase in the amount of PEO. The $g_{\mathrm{h}}$ increases in porous PZT ceramics because of its higher $d_{\mathrm{h}}$ values. This is because, air replaces high value dielectric PZT phase at low permittivity, and increases the $g_{\mathrm{h}}$ value as per (1)

$$
g_{\mathrm{h}}=d_{\mathrm{h}} / k_{33} \varepsilon_{\mathrm{o}}
$$

where $k_{33}$ is the dielectric constant in the poling direction and $\varepsilon_{\circ}$ the permittivity of free space. The highest hydrostatic voltage coefficient measured for PZT porous ceramics using PEO as pore forming agent is $48 \times 10^{-3} \mathrm{Vm}^{-1}$. This value is considerably higher than that of dense PZT ceramic made of the same powder. In reality, continuously increasing the $g_{\mathrm{h}}$ without decreasing ceramic volume, is not practically possible as permittivity decreases, the capacitance declines to a level where its use as an active element for a hydrophone becomes unacceptable.

Figure 3 shows the variation of figure of merit (FoM) and piezoelectric charge coefficient $\left(d_{33}\right)$ with different amounts of PEO and the FoM increases with an increase in the amount of PEO. Because $d_{\mathrm{h}}$ and $g_{\mathrm{h}}$ values increase

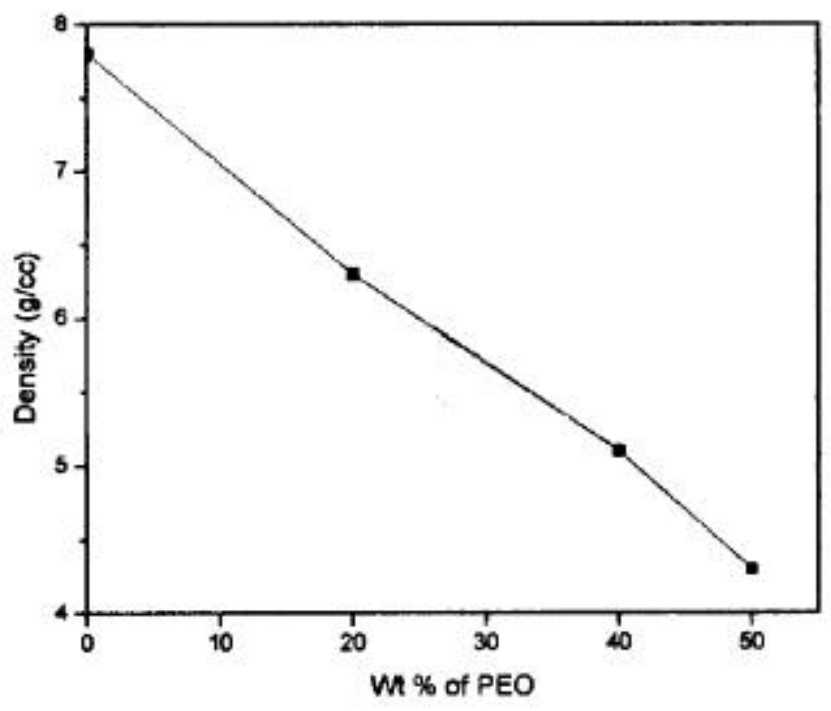

Figure 1. Effect of PEO (wt\%) on density. with increase in the amount of porosity which subsequently increases the FoM values since it is a product of $d_{\mathrm{h}}$ and $g_{\mathrm{h}}$. The reason for high FoM in case of porous PZT ceramics was discussed earlier (Chen and Wu 2004). The $d_{33}$ values of porous PZT ceramics are considerably lower than that of the conventional PZT ceramics, and also it decreases with increase in the amount of PEO. The $d_{33}$ value of porous PZT ceramics is lower than that of conventional PZT ceramics because of the existence of the non-piezoelectric air phase.

Figure 4 shows the scanning electron micrographs of porous PZT ceramics of both high and low porosity (PZT/PEO: 50/50, 80/20). It shows that, when amount of PEO increases the porosity also increases; this subsequently increases the interconnectivities between the

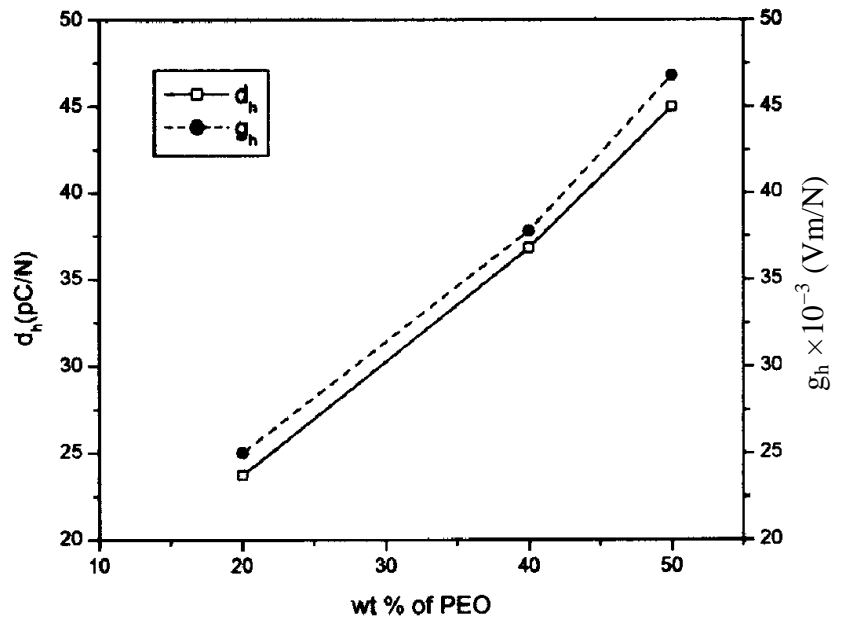

Figure 2. Effect of PEO (wt \%) on hydrostatic charge $\left(d_{\mathrm{h}}\right)$ and voltage $\left(g_{\mathrm{h}}\right)$ coefficients.

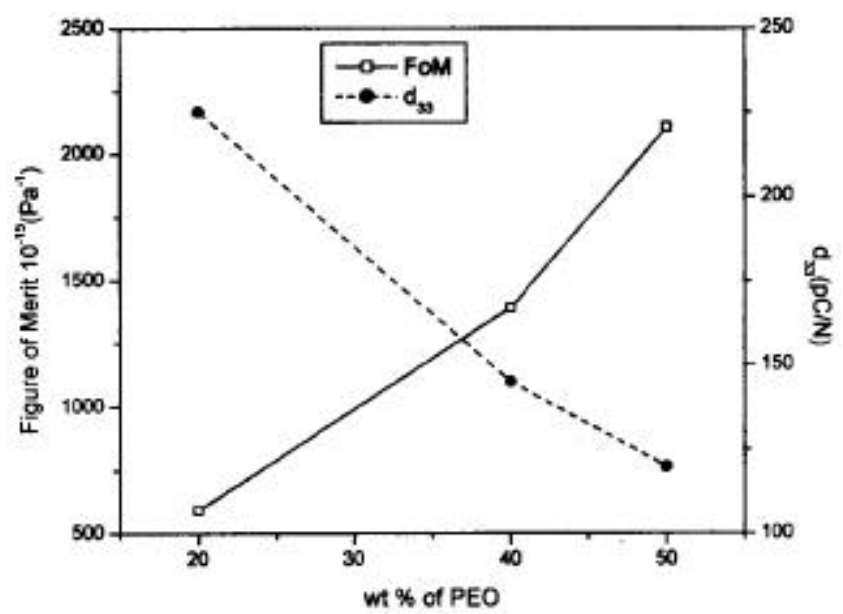

Figure 3. Effect of PEO (wt\%) on figure of merit (FoM) and piezoelectric charge coefficient $\left(d_{33}\right)$. 

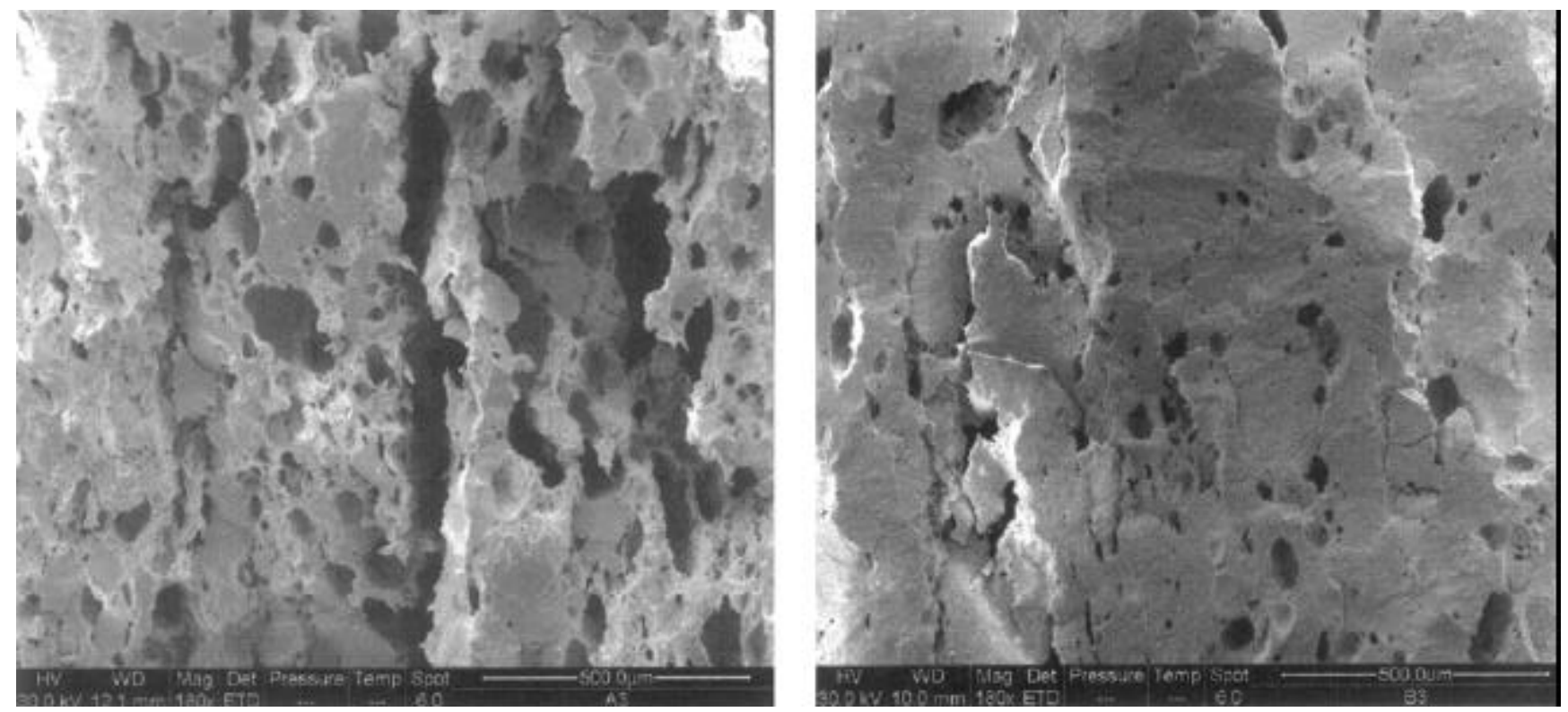

Figure 4. Scanning electron microstructures of high porosity PZT/PEO: 50/50 (3-3 connectivity) and low porosity PZT/PEO: 80/20 (mixture of $0-3$ and 3-3 connectivity) porous PZT ceramics.

pores and pore sizes. Irregular distribution of pores (mixture of 3-3 and 0-3 connectivity) is seen in the low porosity microstructure whereas uniform distribution of pores (3-3 connectivity) is seen in high porosity microstructures. It also shows wide range of pore distribution varying from small micro pores to few macro pores. This change in microstructure is due to the amount of pore forming agent used during the processing of porous PZT ceramics.

\section{Conclusions}

In the present work, porous PZT ceramics were developed by using varied amounts of PEO as the pore-forming agent. At a given sintering temperature, porosity increases with increase in PEO content and both hydrostatic coefficients and FoM increase, with increase in the amount of PEO, whereas piezoelectric charge coefficient decreases with the increase in the amount of PEO. Prominent 3-3 connectivity is seen only in highly porous PZT ceramics (PZT/PEO: 50/50). This porous PZT ceramics with passive air phase could be suitable for the development of high sensitivity hydrophones.

\section{Acknowledgements}

The authors are thankful to Shri A S Rajagopal, Director, Armament Research and Development Establishment (ARDE), Pune, for constant encouragement during this work and Dr R Ramesh, NPOL, Kochi, for technical discussions.

\section{References}

Bowen C R and Topolov V Yu 2003 Acta Mater. 514965

Chen Y C and Wu S 2004 Ceram. Int. 3069

Haertling G H 1999 J. Am. Ceram. Soc. 82797

Li J F, Takagi K, Ono M, Pan W, Watanabe R, Almajid A and Taya M 2003 J. Am. Ceram. Soc. 861094

Newnham R E 1997 Mater. Res. Bull. 2220

Newnham R E and Ruschau G R 1991 J. Am. Ceram. Soc. 74463

Praveenkumar B, Kumar H H and Kharat D K 2004 Proc. of international conference on advanced materials and processing ISAMAP 2 K4 (Kharagpur: IIT) Vol. 11, p. 1151

Ramesh R, Kara H and Bowen C R 2004 Com. Mater. Sci. 30 397

Roncari E, Galassi C, Cracium F, Capiani C and Piancastelli A 2001 J. Eur. Ceram. Soc. 21409

Waller D and Safari A 1988 Ferroelectrics 87189 